\title{
Demand Management and Electricity Supply Industry Reform: A Re-evaluation
}

\author{
B. Stephen Labson
}

$\mathrm{E}$ lectricity sector reform is taking place at a rapid pace in Australia and elsewhere. Victoria, in particular, has embarked on a significant program of reform, whose purpose is to bring about appropriate investment decisions, improved use of existing assets, and incentives for reducing operating and capital costs through a competitive system in which prices send the proper signals to both producers and consumers of electricity and its various services.

Concern has been expressed that, under this deregulated system, appropriate measures related to demand management will be forgone as the industry moves to a competitive system in which the various sub-sectors gain autonomy. For example, Greenpeace (1994:4) cites experience drawn from the UK and Norway noting that 'since the introduction of retail competition utilities have shown little interest in marketing demand management, when not required to do so, and customers are left to differentiate between suppliers on the basis of price'. Greenpeace goes on to argue for regulation that promotes a level of demand management activity beyond that which the market would provide.

Such regulation would be inconsistent with industry reform. For example, to promote demand management activities, Greenpeace has called for the decoupling of sales and profit, and recommends that the introduction of retail competition be postponed where it stifles demand management activity. The significance of these proposals it such as to warrant a re-evaluation of the issue of demand management.

The suggestion that markets are generally unreliable mechanisms for promoting energy efficiency is in my view unsustainable. If market failure is observed, simple and direct measures can be taken that are entirely consistent with reform of the industry. Embedding regulatory demand-management structures in the electricity supply industry is likely to distort the market and to diminish many of the potential benefits of a competitive industry.

\footnotetext{
${ }^{1}$ See also the October 1994 issue of Energy Policy, which is devoted to the topics of energy efficiency and market failure (Huntington, Schipper \& Sanstad, 1994).
}

Stephen Labson is Director of Energy Economics in the Victorian Department of Agriculture, Energy and Minerals, and Chairman of the ANZMEC Integrated Resource Planning Management Committee. 


\section{Defining Demand Management}

The National Grid Management Council (1994:2) has defined demand management as 'any action taken by an electricity utility for the express purpose of influencing how end-use customers use electricity'. Demand management programs are most often characterised as promoting load building, load reduction and load management. These are roughly defined as follows.

Load building. Load building measures are activities that promote an increase in electricity usage. Promoting fuel substitution by replacing competing energy forms with electricity is one important means of load building. Other means include replacing labour-intensive practices with less expensive electricity-driven services. Litthe more will be said about load building measures, since it seems likely that, after deregulation and privatisation, the industry will aggressively market its product to compete with other energy services.

Load reduction. Load reduction measures decrease the amount of electricity used for any given activity through energy-efficiency measures or fuel substitution. Energy efficiency refers to the ratio of the quantity of energy used per unit output of product or service. Typically, capital (for example, home insulation) is substituted for energy input under such measures, whereas fuel substitution may use the same amount of energy, albeit in a different form (for example, replacing electricity with natural gas for residential heating).

Load management. Load management refers to the shifting of electricity demand over time. The most relevant aspects of load management are in 'load shifting', in which electricity demand is moved away from peak load periods, and 'load clipping', in which peak demand is curtailed without a corresponding shift to off-peak periods. An example of peak shifting would be increased industrial usage at night; an example of peak clipping would be an agreed decrease in air-conditioning usage during extraordinary peak load situations.

\section{Objectives of Demand Management}

Demand management potentially offers a means by which to meet a range of objectives relevant to the sector. Such objectives could include correcting for regulatory imperfections that impede the efficient utilisation of capacity, as well as market imperfections that lead to an inefficient mix of energy choices.

Load management and efficient utilisation of capacity. Historically, demand management programs have been targeted at shifting peak load requirements to obviate the need for costly expansions to capacity under market and regulatory uncertainty (for example, the situation in the US described by Gellings, Chamberlin and Clinton, 1987). Such demand measures have been used so extensively, particularly 
overseas, mainly because other distortions had been 'regulated into' the system, giving rise to corresponding measures to offset them.

An example of this round-about regulatory failure was the excess capacity built up in the US into the 1970s stemming from rate-of-return regulation, which often provided an excessive return on capital investment. ${ }^{2}$ In response to this outcome, equally inefficient regulatory measures were undertaken throughout the 1980 s that stifled otherwise economically viable additions to capacity.

It is unlikely that demand management will need to be embedded in the regulatory structure under industry reforms taking place in the domestic market. As reliance on market signals grows, prices will signal the appropriate level of demand by consumers, to be matched by a corresponding supply by generators. The key to obtaining appropriate price signals in a deregulated system is to develop contestable markets at the wholesale and retail levels (though some form of price regulation will be required where contestability is lacking). Under this deregulated structure, the market will provide incentives - 'drivers' - that promote the efficient level of load shifting and load clipping. For example, if peak load prices reflect their full cost, consumers will make appropriate choices as to their level of demand, either shifting it or simply curtailing it if desired. If the value of peak load power is sufficient, it is entirely appropriate for consumers to continue use at their discretion, so long as they pay the economic cost of peak supply. Before the development of sophisticated metering and time-of-day pricing, market based measures such as interruptible contracts can be used to approximate a true cost-reflective market.

Load reduction, energy efficiency and environmental matters. Of the different demand management measures, load reducing programs are particularly relevant to the domestic electricity industry. This follows primarily from environmental objectives, but it is also related to the promotion of an efficient electricity sector.

Under the National Greenhouse Response Strategy (1992:18), public energy agencies are required 'to develop an integrated least-cost planning approach in energy sector planning, involving cost-effective demand management'. This mandate clearly indicates that demand management is to be considered as a measure by which to meet environmental objectives. Furthermore, the mandate for demand management to be 'cost-effective' means that the objective of load reduction on environmental grounds is intertwined with the efficient allocation of resources.

According to the National Grid Management Council (1994:15), where markets are well functioning 'customers would make economically rational choices between, for example, purchasing more electricity and increasing the efficiency with which they use it, depending on the true relative costs of each option'. Does governmentregulated demand management offer a means by which to obtain a cost-effective outcome?

\footnotetext{
2 In an often cited paper, Averch and Johnson (1962) demonstrate that when the allowed rate of retum on capital exceeds its actual cost, profit maximising firms will employ an excessive ratio of capital to labour. In other words, they will tend to over-invest in capital-intensive lactors of production.
} 


\section{The Potential for Market Failure in End Use}

Commonly cited barriers to customer investment in cost-effective demand-side options due to market failure include: the low priority of energy expenditure; split incentives, where the benefits of investment in demand-side options are not adequately capitalised in the value of the asset; the payback gap, in which consumers are assumed to have an overly high discount rate; a lack of information regarding the costs and benefits of demand-side options; and energy prices that do not reflect the true economic costs.

Low priority. It is sometimes observed that consumers are unconcerned about their energy bills because of their relatively small impact on total consumer expenditures. This may well be the case, but it has nothing to do with market failure. A great many other expenditures ranging from snack foods to hardware are made with a similar apparent insouciance. Even though many market participants pay less attention to price than others think they should, these markets function well.

The main point here is that it takes time and effort to employ energy saving processes or technologies. If the cost of this effort outweighs the benefit to the consumer, he or she naturally acts as if unconcerned with energy efficiency. Implementing demand-side measures has a cost in terms of time and effort that cannot be made to disappear by regulation.

Split incentives. It has been argued that a coordination problem may arise when the incentives to invest in demand-side options are split between two or more parties. The typical example of this is the landlord/tenant relationship in which the landlord does not pay for electricity use, and the tenant may not be able to take full advantage of the investment over its lifetime. In this situation, it is alleged that owners tend to minimise initial capital costs without regard for potentially cost-effective decreases in operating costs.

The problem with this argument is that many types of services are built into a lease agreement between landlord and tenant. Any investment in services that a tenant values will be capitalised into the rent. If the landlord sees an opportunity to provide a service that is of value to the tenant, he or she has the proper incentive to provide it in a competitive market. ${ }^{3}$ If this were not the case, and landlords simply minimised initial capital costs, tenants would be living in homes without windows and working in buildings without elevators.

Of course, any such amenity comes at a cost that is ultimately borne by the enduser. That buildings do not always incorporate energy savings measures that provide economic savings over their lifetime for given levels of comfort may simply reflect a consumer's trade-off between cost and comfort. An example of this type of behav-

\footnotetext{
${ }^{3}$ Conceivably, asymmetric information could lead to a 'principal-agent' problem where built-in energy saving measures are difficult to observe on the part of the tenant. In such a case, the landlord will be unable to recoup capital costs through increased rental value. If this is found to be a problem, the best policies are likely to be those that promote the flow of information.
} 
iour is documented in a study undertaken by the Gas and Fuel Corporation of Victoria (1990), which found that households living in dwellings without insulation are likely to heat few rooms, if any. Presumably, they opt to allocate their budget to other items rather than spend it on the additional capital and operating costs associated with keeping a dwelling continuously heated.

The pay-back gap. The idea of a 'pay-back gap' is based on the view that end-use customers typically require a shorter pay-back period for demand-side investments than does the supply industry. The most straightforward evidence for this is the fact that most consumers face higher borrowing rates than industry, which may give rise to market failure in the form of a tendency to under-invest in demand-side options. Sioshansi (1991) has gone so far as to imply that, in effect, a 'free lunch' can be had where industry provides low-cost capital to consumers for investment in such measures.

Unfortunately, this free lunch is more apparent than real. That it is difficult or expensive for some consumers to gain access to capital is not in itself evidence of market failure. Securing a loan requires an offsetting investment. If that investment is risky, perhaps because of the lack of security, the required rate of return will be higher than would otherwise be the case. Since consumers typically present a different risk profile from that of the supply industry, the implied pay-back from demandside investment may be of necessity relatively high. If a uniform rate of return were inposed by regulation across risk profiles, then over-investment would occur in the relatively risky investment.

Consider the proposal that the supply industry offer consumers low-interest loans for investment in energy saving appliances. Assume for simplicity's sake that the most relevant issue is the probability of default on the loan. Presumably, the risk of default by industry is less than that of consumers, thereby leading to a difference in capital costs, or 'risk premium'. Under the proposed scheme, industry would essentially subsidise the risk premium attributed to consumer default and then be made to pick up the additional cost. This scheme has done nothing to lessen the underlying risk of investment, but has simply shifted the cost from consumers to industry. There is a net cost, however, since this subsidy provides excess incentive to take up the relatively costly (risky) investment by consumers, so making the community as a whole worse off.

Lack of information. A rigorous evaluation of the costs and benefits of demandside options often requires expertise on the matter. Sutherland (1991) suggests that a coordination problem may exist whereby the costs of obtaining necessary information could be significantly reduced through scale economies. For example, the cost of determining the energy efficiency of an electrical appliance would be prohibitive for an individual; but if this information were shared among all consumers, the total benefit may outweigh the cost of providing it.

The private market alone may not be able to provide such a service to consumers. If different manufactures follow different rating systems, the consumer may still 
be left with a considerable information problem. But standardsed labelling may provide for coordination among manufactures, while providing a valuable service to consumers. Labelling household appliances is a good example of a simple coordination measure promoting the adoption of efficient demand-side options.

Minimum energy-performance standards are sometimes endorsed in the belief that they rectify the lack of information. But such heavy-handed regulation is not called for when proper labelling measures are adopted. By imposing minimum energy-performance standards, the regulator would be imposing on the community its own preferred trade-off between such factors as cost, energy use and convenience, rather than allowing individual consumers to act on their own trade-offs.

Energy pricing. In open markets, appropriate investment decisions are dependent on prices that fully reflect costs. Where energy is under-priced, irsufficient incentive exists for investment in demand-side options related to load shifting and load reduction.

An example of inefficient load management is pricing peak load power at the same rate as off-peak, which often imposes pressure on peak load capacity. If prices reflect the additional costs involved in supplying peak load power, consumers can make efficient choices about their level of demand.

Uniform tariffs among customer groups may also contribute to an inefficient level of investment in demand saving measures. This can occur when the cost of supplying certain consumers is not fully reflected in the price they pay. Uniform tariffs constitute a subsidy to certain consumers, encouraging excess consumption of electricity and discouraging investment in energy efficiency, fuel switching and alternative technologies.

\section{Indirect Means of Demand Management}

Even where demand-side market failure does exist, it is highly unlikely that the appropriate portfolio of regulatory measures would include those targeted at the supply-side. Simply put, the most efficient means by which to correct market distortion is to employ measures that are targeted directly at particular problems, rather than indirect measures that may or may not hit the mark.

Revenue regulation of the electricity supply industry provides an extreme example of the folly of indirect means of promoting demand-side energy efficiency. Revenue regulation uncouples revenue from sales by setting a predetermined revenue stream whereby price per unit of electricity $(\mathrm{kWh})$ adjusts to changes in the quantity of electricity delivered. The stated objective of revenue regulation is to give the supply industry an incentive to promote measures that reduce the demand for electricity: if its revenue is lixed, the industry's only avenue for increasing profits is to reduce costs.

While revenue regulation may remove the industry's disincentive to provide demand-side savings, it would also remove the incentive to supply electricity. For example, revenue regulation would provide distributors with an incentive to encourage customers to switch from electricity to gas where possible, since whereas the 
distributor's bulk electricity costs are reduced, revenue is guaranteed regardless of the amount of electricity supplied to the consumer. Although fuel switching is appropriate in many circumstances, a biased outcome stemming from perverse incentives is not likely to promote an efficient energy sector.

At a more basic level, it is unwise to impose the presumed demand-side market failure on the supply industry, particularly through the distortion of market signals. If, for example, it is determined that increased information about energy efficiency provides a net social benefit, it would be far more efficient to directly subsidise it in a transparent manner. Funding for such services would most appropriately be provided by government, since presumably the community as a whole would gain from this action. Simply put, the electricity supply industry should be allowed to do what it does best: provide energy services. If market failure exists, it should be addressed directly and transparently.

Other forms of supply-side regulation have the potential to distort the market as well. Regulatory regimes incorporating price capping or rate-of-return regulation, where poorly managed, can provide the wrong signals on which to base economic decisions (see, for example, Beesley and Littlechild, 1989, for a description of issues basic to these forms of price regulation). Where price regulation continues to be justified by lack of contestability (such as in the 'wires' businesses, for example) it is imperative that prices are set such that they reflect true economic costs.

\section{Concluding Remarks}

Demand management was conceived overseas as a tool by which to manage peak load requirements within a capacity-constrained system. Since then a more interventionist view of demand management has become commonplace. The justification of this approach is typically based on the presumption that the market will fail to promote cost-effective investment in demand-side options. However, this presumption is based on weak arguments. Specifically, well functioning markets are often found in sectors that exhibit high initial costs, investment under uncertainty, transaction costs, and split incentives. The presence of such characteristics does not in itself warrant regulation.

Regulators seem strongly tempted to implement a series of compensating distortions under the banner of demand management. Where regulatory intervention has been determined to be appropriate, it will generally be most efficient to implement measures that are targeted directly at the point of failure. If it is a demand-side problem, demand measures should be taken that do not further distort the supply side of the electricity industry.

Markets work best when individuals are allowed to do what they do best. The electricity supply industry should supply the level of electricity services that customers are willing to pay for. It should not be charged with the mandate of also determining what consumers want or need. 


\section{References}

Averch, H. \& L. Johnson (1962), 'Behavior of the Firm Under Regulatory Constraint', American Economic Review 52: 1052-69.

Beesley, M. \& S. Littlechild (1989), 'The Regulation of Privatised Monopolies in the United Kingdom', The Rand Joumal of Economics 20(3): 454-72.

Gas and Fuel Corporation of Victoria (1990), Gas Demand Marragement, Melbourne (Discussion Paper No. 2).

Gellings, C., J. Chamberlin \& J. Clinton (1987), Moving Towards Integrated Resource Planning: Understanding the Theory aud Practice of Least-Cost Planning and Demand-Side Management, Electric Power Research Institute, Palo Alto (Research Project 2548-3).

Greenpeace (1994), Demand Management Opportunities in the Competitive Electricity Market, Mark Ellis, Energy Consultant, Sydney.

Huntington, H., L. Schipper \& A. Saustad (eds) (1994), Energy Policy: Markets for Enengy Efficiency 22(10), Butterworth-Heinemann, Oxford.

National Greenhouse Response Stratcgy (1992), AGPS, Cauberra.

National Grid Management Council (1994), Demand Management Opportunities in the Competitive Electricity MarkeL, Vol. 1: Discussion Paper, Cauberra.

Sioshansi, F. (1991), 'The Myths and Facts of Energy Efficiency', Energy Policy 19(3 ): 231-43.

Sutherland, R. (1991), 'Market Bauriers to Energy Efliciency Investments', The Energy Journal 12(3): 15-34.

The author would like to thank the referees and the Editor for their comments on a previous version of this article. The views put forward in this article are solely his. 